\title{
U.S. INDUSTRIAL FABRICATION OF A 5-CELL SUPERCONDUCTING RADIO FREQUENCY (SCRF) CAVITY*
}

\author{
A. Burger, E. Peterson, Advanced Energy Systems, Inc. ( http://www.aesys.net ) \\ 27E Industrial Blvd., Medford, NY 11763 USA
}

\begin{abstract}
In 1998, a 5-cell, $\beta=0.64,700 \mathrm{MHz}$ superconducting cavity was manufactured by Advanced Energy Systems Inc. (AES) Medford, NY (figure 1). This work was performed under contract to Los Alamos National Laboratory (LANL) through Burns and Roe Enterprises, in association with General Atomics, utilizing customer provided RRR $>250$ niobium and fabrication tooling. This paper will describe the fabrication process including development of a hydroforming process for half cell forming and manufacturing of beam tubes. Testing of the cavity was recently performed at the Jefferson Laboratory cryogenic facility where it exceeded specifications by reaching an $E_{\text {acc }}$ of $9.5 \mathrm{MV} / \mathrm{m}$ at a $Q$ of $3 \times 10^{10}$ with no detectable field emission.
\end{abstract}

\section{INTRODUCTION}

An Engineering Design and Demonstration (ED\&D) program was initiated at LANL within the Accelerator Production of Tritium (APT) Project with the goal of technology transfer to industry for superconducting accelerator components. Advanced Energy Systems Inc. was awarded a contract to manufacture a Medium-beta SCRF 5-cell cavity to the design requirements of the laboratory. The beam tube design included two ports for higher-order mode (HOM) couplers, two ports for power couplers (PC) and one port for the RF pick-up. The performance specification set forth in the program were fundamental accelerating mode frequency of $698.75 \mathrm{MHz}$ at room temperature, field flatness to $+/-10 \%$, and an accelerating gradient $=6.5 \mathrm{MV} / \mathrm{m}$ at a $\mathrm{Q}$ of $5 \times 10^{9}$.

The first step in the cavity fabrication process was to generate a comprehensive manufacturing plan and a plan for process verification. During this initial phase of the program, weld test coupons were prepared with the interlocking joint configuration used in actual cavity construction. A light Buffered Chemical Polish (BCP) to LANL specifications was followed by electron Beam Welding (EBW). After welding each coupon was inspected for full penetration, cracking, drop-through, smooth under bead, no visible start/stop marks. The coupons were then tested for Residual Resistively Ratio (RRR) to insure that the weld had not degraded more than $10 \%$ from the parent material.

\section{MANUFACTURING AT AES, INC.}

Niobium sheet stock RRR $>250$ was received and inspected for defects. Small imperfections were buffed out with scotch brite and the RF side of the material was

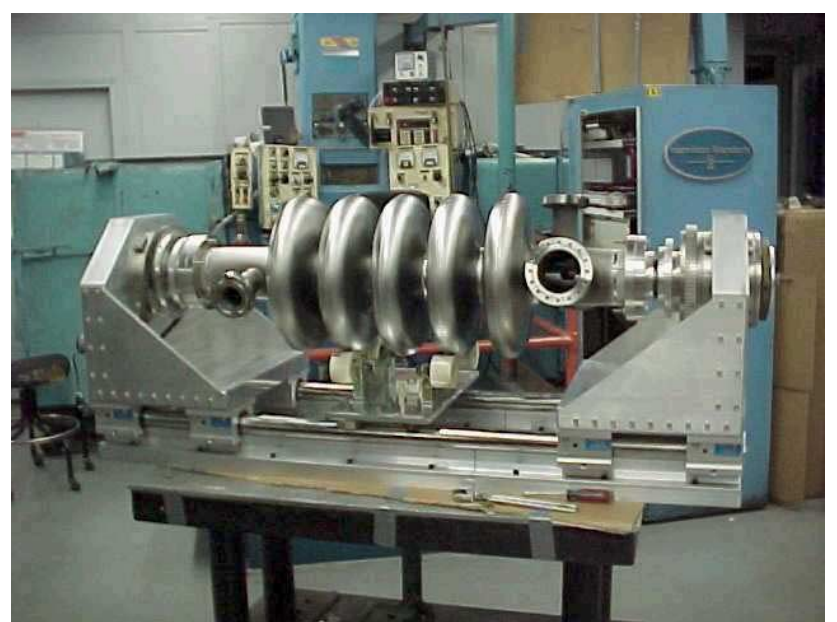

Figure 1 - 5-Cell, $700 \mathrm{MHz}$ RF Cavity

chosen and marked prior to forming. Samples of the asreceived material were taken and the RRR was verified using a measurement set-up with a magnetic field at $4.2 \mathrm{~K}$.

\subsection{Half-Cell Forming}

To form the half-cells, AES elected to use a hydroforming process in lieu of the more traditional punch and die. Experience gained during our initial research efforts showed that minor wrinkling of the niobium sheet resulting from the deep draw forming process did not occur in the hydroformed part (figure 2). This aspect along with the benefit of only requiring a male punch for hydroforming was the basis of this choice. A supplier local to the AES facility, Aero Trades Manufacturing Corp., was selected to form the eight (8) half-cells and two (2) end cells required for the assembly. Prior to forming the niobium half cells, aluminum halfcells were formed to establish the correct disk size, clearance between pressure ring and form block, pressure requirements, and the number of press cycles to form a half cell. The niobium disks were sheared to size and formed with excellent repeatability. Drop-off from the shearing process was collected, identified, and weld test certification coupons were prepared.

\subsection{Half-Cell Machining}

The formed half-cells were returned to the AES facility for machining prior to assembly. Using a numerically controlled (NC) milling machine and tooling to hold the half-cell during machining operations, the inter-locking weld joints were machined into the equator and iris side of the half-cells. Feeds and speeds were carefully 
monitored and controlled to ensure that no part of the niobium exceeded a temperature of $150^{\circ} \mathrm{C}$ at any time.

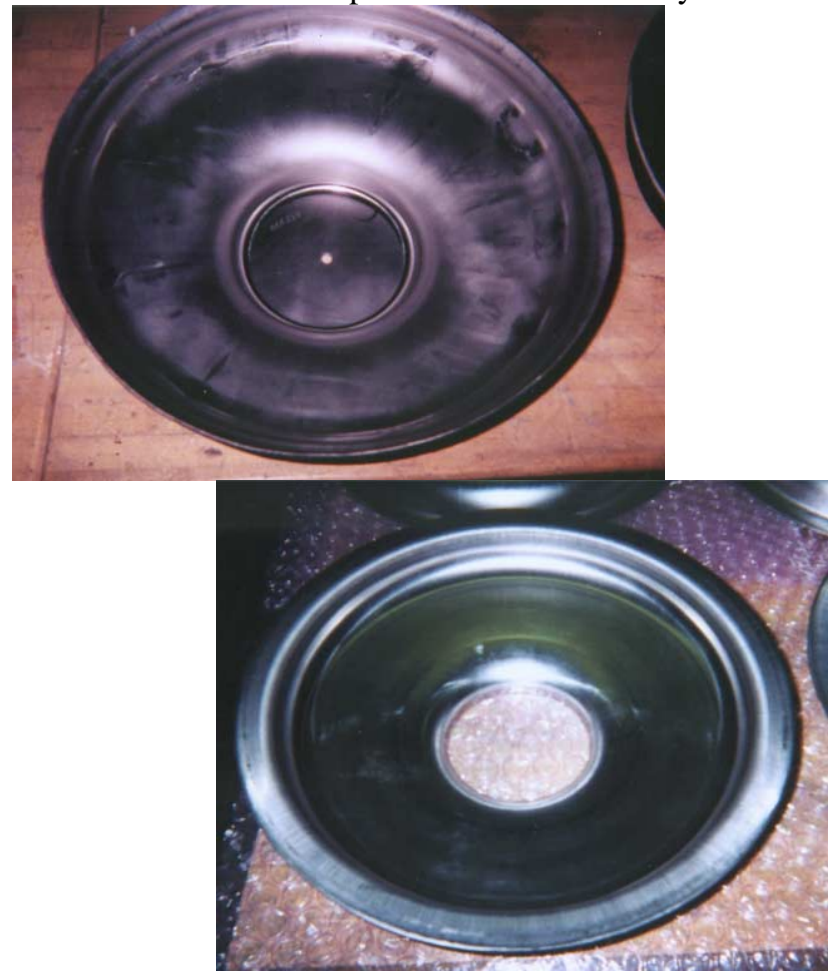

Figure 2. Comparison of Deep Drawn (upper) and Hydroformed (lower) Half-Cells

\subsection{Fabrication of Beam Tubes}

AES had recently completed the design and manufacture of a branch pulling machines and related tooling for LANL. This machine was used to fabricate the two beam tubes from drawn RRR40 grade niobium tubing (figure 3). To form the branches, the tubes were installed in a die block and specially shaped holes are machined through the wall. After deburring and cleaning, each pull location was assembled on the branch pull

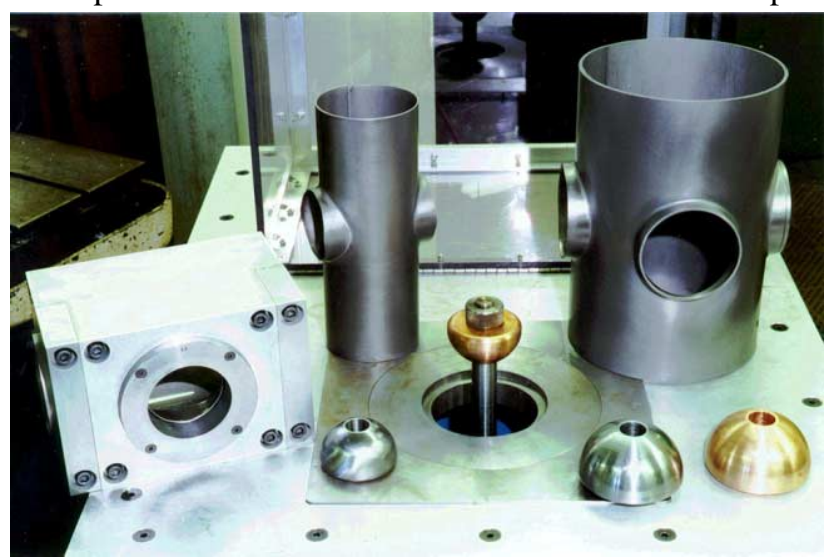

Figure 3. Tube Branch Forming Machine, Tooling and Test Articles

machine with the correct forming hemisphere and the branches were formed. The die inserts were then removed from the assembly and the inter-locking weld joints were NC machined on the end of each branch pull. To complete the beam tube fabrication inter-locking weld joints were $\mathrm{NC}$ machined on both ends of the beam tube.

\subsection{Half Nipple Fabrication}

There were seven half nipples of four different size flanged half-nipples required in the construction of the cavity, two beam tube, two higher-order mode, two power coupler, and one RF pick-up. Each half nipple is a brazed assembly that consists of a RRR40 grade niobium drawn tube and a stainless steel Conflat ${ }^{\mathrm{TM}}$ flange. To ensure that half nipples are concentric and parallel they are final machined after the vacuum braze operation. Prior to brazing the niobium tubes were machined to have a 5 degree taper on one end. This taper was then gold plated to facilitate a good braze. An over sized stainless steel disk was then machined with a matching 5 degree angle on the inside diameter to fit the niobium tube. These parts were then transported to another local supplier, Martin Kurz \& Co. Inc. (MKI), where AES staff worked with MKI personnel in assembling the parts into braze tooling. The assemblies were then vacuum brazed with Nioro (Au$82 \%, \mathrm{Ni}-18 \%)$ and returned to the AES facility where the final stage of fabrication was completed. The first stage in completing the half nipples was to thermally shock each assembly and leak check to ensure an acceptable braze joint. Final operations consisted of machining the stainless steel disk to create a Conflat ${ }^{\mathrm{TM}}$ flange and machining the inter-locking weld joint on the end of the niobium tube.

\subsection{Electron Beam Welding}

Electron Beam Welding of the parts was performed at EBTEC Corporation in Agawam, MA. Again, AES personnel worked with EBTEC staff at their facility to develop welding parameters and support all assembly operations. The welding equipment used was a Hamilton Standard $150 \mathrm{kV}$ system 36 "x 36 " cross section chamber. The team identified 18 weld cycles to fabricate a single five-cell cavity. Prior to welding operations at EBTEC, a light BCP was performed at the AES facility on all weld joints using 1:1:1: acid composition by volume of nitric, hydrofluoric, and phosphoric acids. After chemical processing, the parts were placed in nylon bags, back filled with ultra-high purity dry nitrogen, and transported to the EB Weld facility. The physical size of the cavity required careful planning of the weld sequence to ensure a line of sight for each successive weld. The first subassemblies welded were the half nipples to the beam tubes with each assembly requiring three tooling set-ups. The next weld operation assembled the beam tube subassemblies to the end half cells with an internal weld at the iris. At this stage of assembly four half cells are added to each end sub-assembly one at a time alternating equator and iris welds. The final EB weld joins the two half-cavity sub-assemblies at the center cell equator joint. Following visual and $\mathrm{x}$-ray inspection, the cavity was transported back to the AES facility for leak testing and low power RF testing. The cavity passed all tests and met 
all as-built, pre-BCP frequency and field flatness requirements. The cavity was delivered to LANL in November 1998, 5 months after contract award.

\section{CAVITY PERFORMANCE TESTING}

The completed cavity (figure 4) saw it's first cold testing at Jefferson Laboratory in Newport News, Virginia during 2000. The cavity was tuned to the frequency and field flatness required for testing. Preparations were then begun for the 1:1:2 BCP treatment to remove $\sim 150 \mu \mathrm{m}$ of $\mathrm{Nb}$ from the cavity inner surface. Process parameters called for acid circulation for 14 minutes $(7 \mathrm{~min}$. forward / 7 min. reverse) at an acid temperature of $4^{\circ} \mathrm{C}$. This was followed by filling and draining the cavity six times with de-ionized water at $40^{\circ} \mathrm{C}$. A High Pressure Rinse (HPR) was then performed for 2 hours. The cavity ports were bagged inside the HPR cabinet and it was moved into the clean room assembly area in a vertical position for final assembly preparations for cryogenic testing [1].

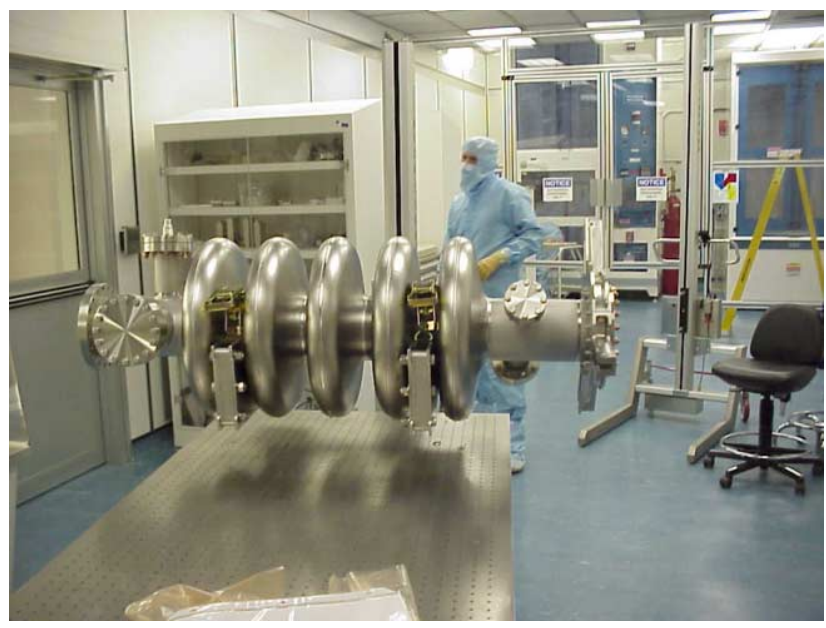

Figure 4.

Preparation for RF Testing at JLAB

Test results for the AES cavity are presented in Figure 5. The maximum accelerating gradient reached during the tests was limited by the available RF power and further testing is required to determine the true cavity limits. The

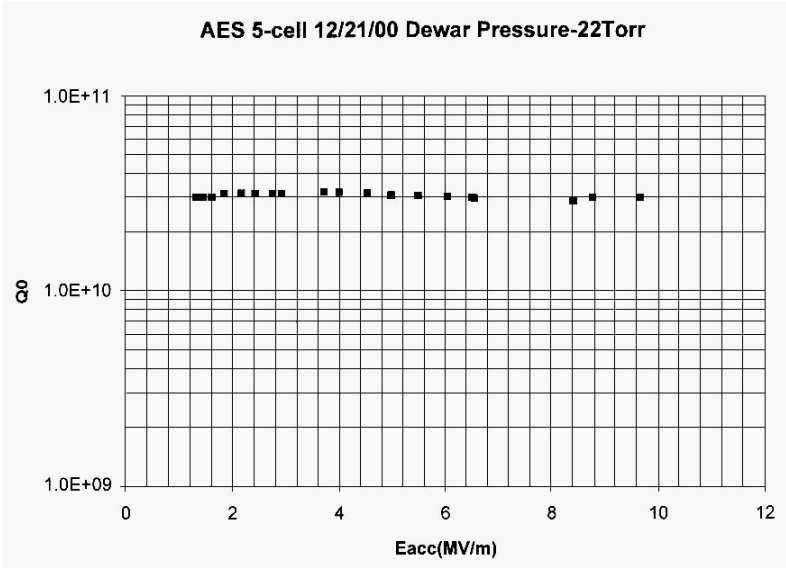

Figure 5. Measured Performance of SCRF Cavity results of the last run at $2 \mathrm{~K}$ were an $\mathrm{E}_{\mathrm{acc}}=9.5 \mathrm{MV} / \mathrm{m}$ (exceeding the APT design goal of $6.5 \mathrm{MV} / \mathrm{m}$ ) at a $\mathrm{Q}$ value $3 \times 10^{10}$ with very low field emission.

\section{CONCLUSION}

A successful technology transfer program between Los Alamos National Laboratory and U.S. Industry has recently been completed with the manufacture of a five cell $700 \mathrm{MHz}$ superconducting cavity by Advanced Energy Systems Inc. The cavity has exceeded APT program design goals. Innovative forming techniques utilized during the fabrication process resulted in improved quality characteristics and reduced cost. Continued support of ED\&D programs for the fabrication of superconducting cavities is essential to improving the technology and identifying cost drivers in rate production.

\section{ACKNOWLEDGEMENTS}

The authors would like to express their gratitude to the many people that supported this fabrication and test effort. Thanks to our suppliers, Aero Trades Mfg. Corp., EBTEC Corp. (http://www.ebteccorp.com) and Martin Kurz \& Co. Inc. (http://www.mkicorp.com) for their dedication to supporting the development of manufacturing parameters. We are particularly grateful to R. Gentzlinger, LANL, J. Kuzminski, GA, and C. Lee, NGC for their support during fabrication of the cavity and J. Mammosser and his team at Jefferson Lab. for their expertise during testing.

\section{REFERENCES}

[1] J. Mammosser, Private Communication. 